\section{EMBRYAIDDLE \\ Aeronautical University}

SCHOLARLY COMMONS

\section{International Journal of Aviation,} Aeronautics, and Aerospace

\title{
MINDSPACE and Development of Organizational Culture in Aviation Safety Management
}

Wilson Gilliam Jr

Embry-Riddle Aeronautical University, liverotor@gmail.com

Follow this and additional works at: https://commons.erau.edu/ijaaa

Part of the Applied Behavior Analysis Commons, Business Administration, Management, and Operations Commons, Cognitive Psychology Commons, Educational Psychology Commons, Higher Education Commons, Human Resources Management Commons, Organizational Behavior and Theory Commons, Public Affairs, Public Policy and Public Administration Commons, and the Theory and Philosophy Commons

\section{Scholarly Commons Citation}

Gilliam, W. (2019). MINDSPACE and Development of Organizational Culture in Aviation Safety Management. International Journal of Aviation, Aeronautics, and Aerospace, 6(1). https://doi.org/ 10.15394/ijaaa.2019.1314

This Position Paper is brought to you for free and open access by the Journals at Scholarly Commons. It has been accepted for inclusion in International Journal of Aviation, Aeronautics, and Aerospace by an authorized administrator of Scholarly Commons. For more information, please contact commons@erau.edu. 


\section{MINDSPACE and Development of Organizational Culture in Aviation Safety Management}

\section{Cover Page Footnote}

Acknowledgements To my family, who have sacrificed cello practice and playing with the dog to provide the noise reduction necessary for intense research. Carry on. You have my full attention. 


\section{Introduction}

The aerospace industry is dependent upon safety for success. Without predictably safe operations, aviation travel would lack the trust and confidence of the public, causing revenue reductions, discontinued passenger routes, and cessation of some ancillary services. Aviation safety management systems (SMS) are tools that the industry uses to establish and maintain safety, predicting weaknesses and implementing remedial actions. SMS rely on an organizational culture of error reporting and safety-related processes that pervade every facet of planning, operations, and business structure all operating within a non-punitive atmosphere called a just culture (Darveau \& Hannon, 2017; Dekker, 2014; Reason, 1990).

Establishing the proper organizational culture is a prerequisite for a working SMS (Dekker, 2014). Building or remodeling company culture can be hindered by obstacles. There are human biases within every company that act as barriers to the establishment of the type of culture that supports the systemic implementation that SMS requires. These biases act as influential factors on the SMS, limiting its effectiveness.

\section{Background}

Human biases can be overt and discriminatory, acting as illegal and socially unacceptable barriers to the foundation of safety culture (Jones, Arena, Nittrouer, Alonso, \& Lindsey, 2017). Other biases can be subtle, resulting from cognitive evolutionary processes evolving over many thousands of years (Jones et al., 2017). These subconscious biases are thinking accelerators acting on human cognitive reflexes (Howard, 2017) being referred to as "system 1" type thinking, based on impulse and habit mechanisms devoid of most logical thought patterns (Liu, Vlesy, Fang, Denrell, \& Chater, 2017).

Traditional solutions for dealing with human biases have included both education and recognition (Liu et al., 2017). These types of coping tools engage logical thought and have proven to have limitations (Derous, Buijsrogge, Roulin, \& Duvck, 2016). This position paper offers an alternative method for engaging human bias and evaluates the potential of system 1 type thinking in dealing with system 1 type biases, improving the success of organizational culture necessary for SMS to flourish. This paper studies the application of a system called MINDSPACE (Liu et al., 2017) during the process of establishing company just culture.

Most traditional interventions against human biases employ logical thought and reflection, which are considered "system 2" thinking. Reducing human biases with "fight fire with fire" approach, matching system 1 solutions against reflexive biases in an aviation context, is the purpose of this paper (see Figure 1). 


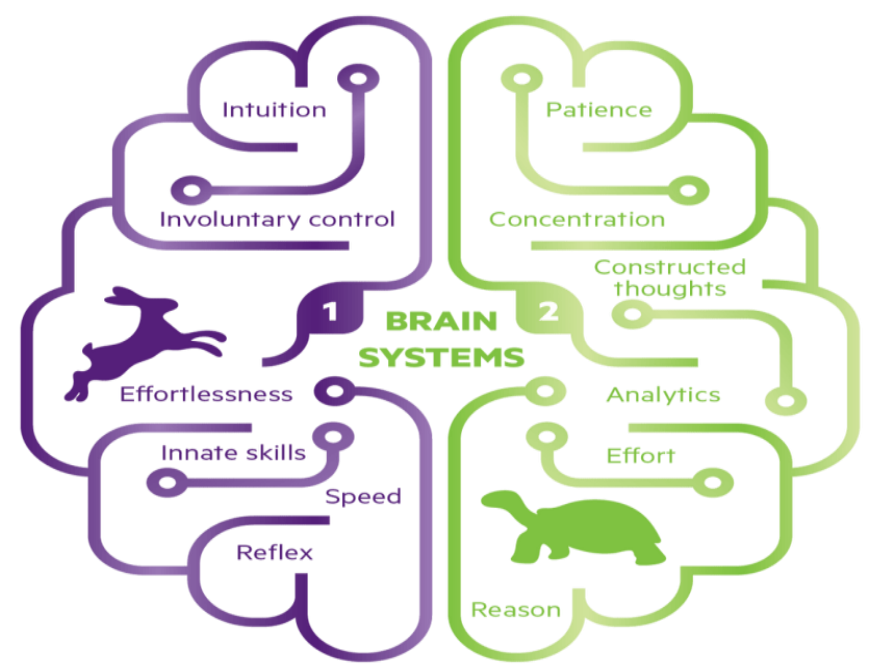

Figure 1. Differences between system 1 and system 2 thinking in humans.

Reprinted from 'The pseudo-nuero science of business thinking...fast or slow, left or right, logic or emotion, system 1 or 2.' Retrieved from https://www.thegeniusworks.com/2017/05/the-pseudo-neuro-science-of-businessthinking-fast-or-slow-left-or-right-logic-and-emotion/. Copyright 2017 by Peter Fisk.

Current research has identified human biases as leading obstacles to efficient SMS function (Darveau \& Hannon, 2017; Jausan, Silva, \& Sabatini, 2017; Liu et al., 2017). Human biases often work contrary to corporate efforts intent on establishing cultures boosting SMS potency (Baybutt, 2016; Bellamy, Chambon, \& Guldener, 2018; Derous et al., 2016; Emmons, Mazzuchi, Sarkani, \& Larsen, 2018; Gubbins, Harney, Vanderwerff, \& Rosseau, 2018). Reducing the overall impact of these biases on the development of organizational safety culture with modern alternatives is the purpose of this paper.

Organizational culture is the fertile ground that permits SMS to be effective. Culture allows the establishment of the four pillars of SMS which are safety policy, risk management, safety assurance, and safety promotion (Stolzer \& Goglia, 2016). Establishing a culture that is open to and dedicated to developing these four safety concepts in the most primary step in the effective function of SMS.

\section{Statement of the Problem}

Establishing a safety culture at the organizational level involves a commitment from the top leadership, appointment of a safety advocate, and adoption by upper- and mid-level divisional managers (Stolzer \& Goglia, 2016). 
The problem is that human biases interfere with the establishment of culture, the primary step in establishing an effective SMS.

Mitigating human bias in real-world situations remains elusive, despite a saturation of research on human bias and its negative consequences on organizational efficiencies (Liu et al., 2017). The current body of research related to human biases supports the relationship of systemic bias with the presence of organizational barriers impeding the performance of SMS (Jausan et al., 2017).

Research identified four predominant human biases called anchoring bias, optimism bias, planning fallacy bias, and ambiguity bias (Emmons et al., 2018). Given the limitations of traditional strategies to effectively counter human biases, the MINDSPACE alternative system was evaluated to ascertain its potential impact to confront these four biases within the context of organizational decision making specifically related to establishing and maintaining a just culture.

\section{History of Safety Management Systems}

\section{Review of the Relevant Literature}

SMS are active within various industries. Many types of SMS have emerged within transportation industries to identify, manage, and preclude accidents (Naevestad \& Hesjevoll, 2018; Ranney et al., 2018). The majority of SMS share certain characteristics in that they are structured, actively managed systems supported by leadership, designed to control risks, and prevent accidents (Li \& Guldenmund, 2018).

Aviation SMSs began to evolve from the developed structure of quality management systems (QMS) emerging from mature businesses in the 1960s. Quality management has been a focus for goods manufacturers and proprietors for millennia, but the organized QMS emphasis on planning and building a quality system with repeatable processes along with measuring performance is considered the basis for modern aviation SMS systems (Stolzer \& Goglia, 2016). Aviation SMS were developed over time as technical improvements combined with human factors studies and business-related QMS programs began to influence an organized approach to aviation safety (Federal Aviation Administration [FAA], 2016).

\section{Purpose of the Aviation SMS}

Aviation SMS success requires the identification of hazards, potential hazards, and management of risk. The FAA defines a SMS as "the formal, topdown, organization-wide approach to managing safety risk and assuring the effectiveness of safety risk controls. It includes systematic procedures, practices, and policies for the management of safety risk" (2018, para. 1). The aviation SMS is a decision-making tool that is reactive and proactive in eliminating known and unknown risks, supported within an organizational culture that facilitates error reporting, dedicated to the continuing discovery of hazards (Dekker, 2014; Stolzer \& Goglia, 2016). 
There are four fundamental, structural elements of an aviation SMS: safety policy, safety risk management, safety assurance, and safety promotion (Stolzer \& Goglia, 2016). Each pillar of SMS may support sub-systems which can enhance effectiveness. The four elements are introduced below (see Figure 2).

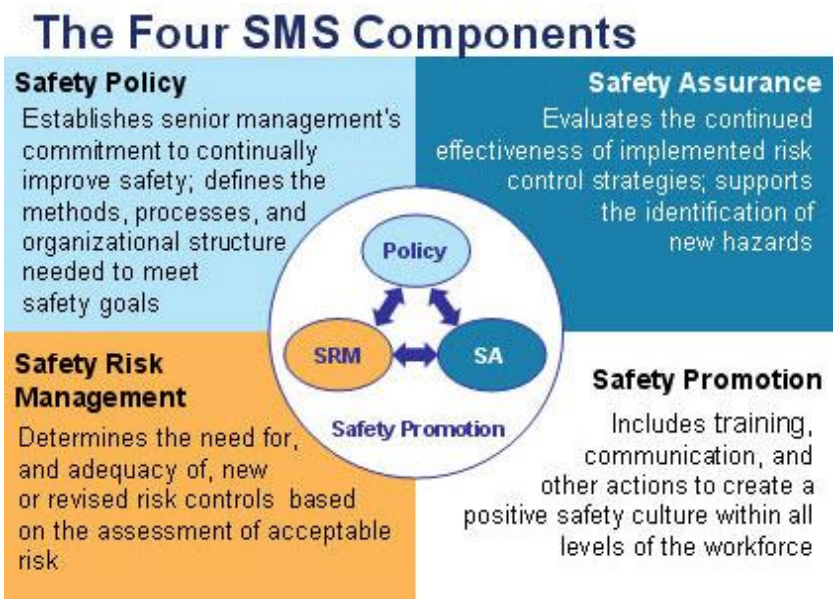

Figure 2. The four main components of an aviation safety management system. Reprinted from (FAA, n.d). Retrieved from https://www.faa.gov/about/ initiatives/sms/explained/components/

Safety policy refers to the dedication by upper levels of management to provide a "just" culture in which unintentional mistakes are not punishable and error reporting becomes normal behavior. The just culture is a primary requirement for SMS to function properly because it provides objective information about root causes for mistakes which aid ongoing efforts to identify hazards and interrupt them. Barriers that prevent the establishment of a just culture will reduce the effectiveness of an aviation SMS (Baybutt, 2016; Bellamy et al., 2018; Darveau \& Hannon, 2017; Dekker, 2014; Emmons et al., 2018).

Safety risk management is the second pillar of SMS and is related to the processes of hazard identification, risk identification and mitigation of both. Each company will have its own safety objectives, along with operational and financial constraints. This means that every safety risk management program for each aviation SMS will be structured differently. These risk management programs should not be thought of as pattern-type systems and each SMS must be evaluated and its performance measured on its own merits (Stolzer \& Goglia, 2016).

Safety assurance is the third pillar of SMS and involves the actions necessary to verify that established hazard identification and risk management tools are acting effectively (Waddington, Lafortune, \& Duffey, 2009). This part of a SMS deals with internal and external auditing, data collection, and performance measuring. A critical element of safety assurance is the constant inflow of objective 
error reporting data submitted through voluntary reporting systems (VRSs) (Robertson, 2016). Safety assurance is an important SMS function as it verifies that risks are being identified, mitigated and controlled.

Safety promotion is the final element of an SMS and is related to the topdown management support of culture, safety education and mode of information sharing. Safety promotion also informs employees about the success of recent safety efforts to include the effectiveness of VRSs (Stolzer \& Goglia, 2016).

\section{System 1 Versus System 2 Thinking}

It is important to clarify the differences between system 1 and system 2 thought processes since both are used as tools for reducing human biases. System 1 thinking is impulse and habitually driven while system 2 deliberations are more logical and determined (Derous et al., 2016; Liu et al., 2017). A system 1 bias example would involve an internal feeling of positive kinship between an applicant review board panelist and a job interviewee that comes from a similar educational, vocational, or geographical background. Given the same example, a system 2 response would be to ignore those feelings of camaraderie and focus on written checklist tools, analysis processes, and performance-based criterion for judging purposes.

\section{Research Approach}

\section{Methodology}

This research was conducted as a comprehensive literature review to determine the extent of scholarly research involving human bias and how biases may impact the effectiveness of SMS. The research included the goal of discovering the most common barriers to an effective safety system, noting that most of these impediments included human bias in some form. All parts of the SMS were considered to include the safety culture, safety policy, safety risk management, safety assurance, and safety promotion.

\section{Design and Procedures}

Numerous scholarly, peer-reviewed databases were consulted, emphasizing publications within the past three years. The systemic literature review resulted in the initial consideration of 86 sources, with the final source data emanating from references on human biases, organizational barriers, and remedies for counteracting biases having an impact on SMS effectiveness.

\section{Treatment of the Data}

Survey data from multiple sources were collected regarding barriers to SMS effectiveness. The overall goal was identification of common themes in the data that represented the most common barriers to SMS effectiveness as recognized by transportation industry experts. This was accomplished by assigning barriers into categories. The categories were organizational, individual, and working environment. Sixty-two different barriers to SMS were identified across five 
studies. There were 29 organizational barriers, 18 individual barriers, and 23 working environment barriers identified across all studies identified within the literature. Four barriers were included in all categories because they describe human biases that are applicable in some form across all types of organizational structures. As a result of organizational influences on safety culture, an emphasis on organizational barriers to SMS was chosen (Li \& Guldenmund, 2018).

\section{Results}

The results from the literature review and subsequent data analysis revealed that human biases are systemic in the workplace. Within the aviation industry, human biases at the organizational level were discovered to have the most negative impact on establishing a just culture in which an SMS can effectively operate. The results also suggested that there are four biases that are predominant in propagating breakdowns in SMS effectiveness: optimism bias, planning fallacy bias, anchoring bias, and ambiguity bias. Results indicated that potentialities exist for deploying system 1 cognitive solutions within aviation businesses to combat human biases and strengthen the establishment of a strong just culture. The results also suggested that custom designed solutions may include both system 1 and system 2 approaches. Finally, the existence of a strong entrepreneurial culture may serve to inhibit the establishment of a safety just culture, especially if the owner(s) do not recognize the biases evident in their decision-making.

\section{Organizational Barriers are Important}

Human biases at the organizational level were shown in the research to impact SMS effectiveness by impeding the establishment of a just culture (Darveau \& Hammond, 2017; Emmons et al., 2018; Ioannou et al., 2017; Jausan et al., 2017; Naevestad et al., 2018). A just culture requires an objective corporate mindset intent on constructing an atmosphere of trust which fosters voluntary error reporting (Darveau \& Hammond, 2017). The data showed that when human biases are permitted to exist, or are used in decision-making, certain vulnerabilities in a just culture can be created. Some of these weaknesses are managerial self-protection mechanisms, protection of status, overconfidence, overt discrimination, and resistance to change (Baybutt, 2016; Bellamy et al., 2018; Dekker, 2014; Derous et al., 2016; Howard 2017). Moreover, since these biases exist at the organizational level and due to their negative impact on the development of a just culture, biases must be recognized, managed, and controlled.

Two general schools of thought emerged within the research aimed at reducing optimism bias, planning fallacy bias, anchoring bias, and ambiguity bias at the organizational level: system 1 and system 2 based cognitive solutions.

\section{Traditional Solutions are Ineffective}

Liu et al. (2017) noted the ineffectiveness of standalone system 2 cognitive solutions. System 2 thinking seeks to recognize that human biases exist and "de- 
bias" the decision-making process (p. 135). Liu et al. argued that system 2 solutions attempt to rationalize instinctual, rapid impulse decision-making (system 1), and is therefore not compatible with strategizing solutions to system 1 biases.

The entirety of the data included in this report also supported the concept that the sole use of system 2 cognitive tools aimed at reducing human biases is not effective. Prima facia evidence for this conclusion abounds since there is evidence that despite the deployment of system 2 tools, human biases remain pervasive (Jones et al., 2017; Malos, 2015).

\section{MINDSPACE - A New Framework}

The MINDSPACE framework offers relatively new potential for managing human biases. MINDSPACE seeks to motivate human behavior by altering the context of the decision-making process so that system 1 cognition is more aligned with organizational culture (Liu et al., 2017). This is accomplished by "using one bias to overcome another bias" versus "changing the mind" (pp. 136-137). MINDSPACE attempts to motivate human behavior by manipulating responses to impulsive and habitual cognitive reflexes.

The MINDSPACE system is based on a book called The Nudge and was originally proposed by Dolan et al. (2010) to the government of the United Kingdom in analyzing how governmental policy changes may impact human behavior. Since that time, use of the MINDSPACE approach has widened, spreading into pharmacological (O'Sullivan, Ryan, Downey, \& Hughes, 2016), healthcare (Vlaev, King, Dolan, \& Darzi, 2016), and industrial settings (Liu et al., 2017). Based on its continued success and adoption by other industries, MINDSPACE shows promise for aviation applications.

The MINDSPACE nine system 1 interventions and brief explanations are shown below: 
Table 1

MINDSPACE Acronym and Definitions

\begin{tabular}{|l|l|}
\hline (M) Messenger & $\begin{array}{l}\text { People are influenced by who communicates } \\
\text { information }\end{array}$ \\
\hline (I) Incentives & Human beings have mental shortcuts to prevent "losses" \\
\hline (N) Norms & $\begin{array}{l}\text { People are strongly influenced by what others do and } \\
\text { what is considered normal behavior }\end{array}$ \\
\hline (D) Defaults & People tend to stick with pre-determined options \\
\hline (S) Salience & What is unique and relevant draws human attention \\
\hline (P) Priming & Human behavior is influenced by "subconscious cues" \\
\hline (A) Affect & $\begin{array}{l}\text { Emotional associations can be powerful human } \\
\text { motivators }\end{array}$ \\
\hline (C) Commitments & $\begin{array}{l}\text { We honor public commitments and tend to reciprocate } \\
\text { acts }\end{array}$ \\
\hline (E) Ego & Humans act in ways that protect, preserve the self \\
\hline
\end{tabular}

Note. Adapted from Dolan et al., (2010). MINDSPACE: Influencing Behavior Through Public Policy, p. 6.

The core element of the MINDSPACE approach is that it uses one of, or a combination of, the above nine interventions to alter the context of the decisionmaking process to align system 1 solutions with system 1 type problems (associated with human biases in this case).

MINDSPACE can benefit companies aiming to establish just cultures as a basis of effective SMS. Strategizing with MINDSPACE may be both creative and scientific processes, with final solutions aimed at initial corporate and internal error reactionary measures being more about safety, efficiency, and performance, rather than punishment.

Each of the MINDSPACE interventions are listed below, but only briefly. They are shown in italics when referencing a specific MINDSPACE letter. The reader should use this basic information to further their knowledge about MINDSPACE and system 1 interventions, especially within aviation applications. Messenger

People attach meaning to information disseminated by those that are considered experts of knowledgeable. The messages often act as an anchor, especially when listeners may not be well-versed about a particular subject. The significance of the messenger within the context of MINDSPACE is that the message may be manipulated to achieve the desired human behavior. If objectivity is crucial, then anonymity should be promoted and only the message itself delivered. In establishing a just culture at the organizational level, messengers have significant influence over the strength of the overall impact of the efforts (Dolan et al., 2010). 


\section{Incentives}

Most human beings will go to great lengths to avoid financial and or social losses. Incentives is a powerful MINDSPACE interdiction as it allows planning around many of the shared characteristics that the aviation industry shares with other business segments: competition, product and services promotion, business health and success, personal career growth, and other factors. Planners may utilize this "fear of losses" to guide thinking to more closely parallel organizational goals. This intervention may assist company leaders with establishing just cultures because most people tend to avoid punishment and reciprocate respectful behavior (Dekker, 2014).

\section{Norms}

Most people do not enjoy being categorized as outside of being "normal." Past research has indicated that people will go to great lengths in avoiding being labelled as abnormal or existing outside of normal behavior.

The use of norms can be a powerful tool when establishing a safety culture. This strategy may act as a leverage point (and combine with other MINDSPACE interventions) for top leadership to persuade mid-level managers to accept the new culture and support it. Another possibility is to establish teams of employees across all operational divisions that can participate, contributing ideas to culture development but through a well-designed input mechanism intended to elicit acceptance of the final product. This would also involve the use of commitments, the $\mathrm{C}$ in the MINDSPACE framework. The planned participation of all employees signals management's readiness for across the board input, engaging in "normal" face to face interactions and a new way of doing business (Liu et al., 2017).

\section{Defaults}

People do not enjoy changing selections, especially when it involves possible losses. Organizational leaders should utilize MINDSPACE to establish culture-related default policies that encourage adoption of just cultures. This may involve establishing internal, decision-making roadmaps that require a certain number of managers agree (or disagree) on a topic. This process then becomes the default way of making decisions throughout the organization.

Utilizing defaults to enhance aviation just cultures can include many things such as using automatic generation of anonymous user accounts for VRS log in as part of the onboarding process for new employees. This default setting allows everyone within the organization to have an anonymous account, followed up by human resources's training on the use of and effectiveness of VRSs. Within the organization, other default policies are available and may include pilot and crew shuttles that utilize hotels without all- night clubs attached (to reduce temptations to drink alcohol late in the evening). The ideas are limitless, involve changing the context (not the mind) and involve specific organizational goals. 


\section{Salience}

Salience is a MINDSPACE intervention that acts on a human being's evolutionary impulse to anchor information. Salience makes us choose things because they are deemed important or critical to a process or simply because the object, idea or policy is more noticeable and available. An example of salience is the successful increased sales of milk versus soda in a cafeteria due to milk being placed more directly in front of young consumers and soda being placed farther away. This is the concept of salience.

Salience can be useful in establishing just cultures when strategists use it to manipulate influences to overcome established or "old" ways of doing things. While the traditional punishment for errors may be monetary, a reprimand or even employment termination, salience keeps the focus on the determination of root causes and determination of hazards (Liu et al., 2017).

\section{Priming}

Priming means that as people, we often base our decision-making on subconscious ques that are beyond the scope of the issue at hand. Despite having years of experience in human biases, judges have higher conviction rates when the weather is bad. This type of system 1 process is difficult to correct because even if identification of such behavior is available in research, it still exists and recorded as systemic.

Priming may impact the establishment of just cultures by encouraging leadership to respond negatively to any policy changes resulting in a loss of income (this could also be part of incentives). To counter priming and encourage acceptance of the just culture, the context of the situation could be altered to show the benefits to the company's competitiveness and attractiveness toward previously unidentified market segments. By altering the context way from finances, the focus is shifted toward stability and potential growth (Jones et al., 2017; Liu et al., 2017). Affect

Affect involves human emotions. Results that have negative emotional impact tend to be avoided. The FAA recognizes the impact that affect has on new students undergoing flight training. In the Aviation Instructor's Handbook, the FAA discusses the Law of Effect: "Thus, learning is strengthened when accompanied by a pleasant or satisfying feeling, and (sic) weakened when associated with an unpleasant feeling" (FAA, 2008, p. 2-11).

Affect is a core argument against punishing accidental errors. Internal policies should reflect as much positive emotional support and reaction as possible when establishing just cultures, especially if there is a transition necessary to achieve it. Moving from the traditional ways of "doing things around here" to a vibrant, forward thinking just culture may create negative emotional responses from some. There should be a strategy to guide and manage those feelings. 


\section{Commitments}

People normally honor public commitments and reciprocate good behavior (Liu et al., 2017). Strategist for just culture development should note that commitment becomes even more successful when costs of failure becomes elevated (Dolan et al., 2010). In developing just culture, it is important to obtain firm commitments from messengers and other managers to support and promote the changes. Public commitments to the just culture would be most effective, especially when linking the lack of commitments to loss (as in a loss of business to a competitor).

\section{Ego}

Ego means that people act in ways that tend to elevate themselves. Ego is a complex subject, as the term also includes ancillary situations and conditions with which the ego interacts. People contemplate their own behavior and performance as being superior to others, when the opposite may be true. Ego is a powerful heuristic that may be combined with other MINDSPACE interventions to create novel solutions. Ego may be problematic when establishing a just culture that enhances SMS effectiveness. To counter $e g o$, the context must be changed so that ego is acted "with" in developing solutions to just culture implementation (Dolan et al., 2010; Liu et al., 2017). An example of utilizing ego to organizational advantage would be to recognize work efforts based on their contribution to the culture, rather than their personal achievements.

\section{MINDSPACE and Optimism Bias}

Optimism bias can reduce an organization's attempts at establishing the just culture necessary for an effective SMS. Optimism bias creates the illusion that one is at a reduced risk of experiencing and having to deal with the consequences of a negative event, compared to peers. When CEOs and upper level managers are influenced by this bias, they may propagate that invulnerability into the culture planning process, assuming that existing risk identification and management programs are effective "enough" (Emmons et al., 2018). Optimism bias may be strengthened by a clean accident record and result in dangerous complacency. Optimism bias may influence corporate leaders to skip safety meetings and participation in safety-related activities. Crafting a custom MINDSPACE approach against optimism bias would depend on the details of each situation. In general, leaders must be "obsessed" with safety in such a way that it becomes the norm for the organization (National Transportation Safety Board, 2013).

Another MINDSPACE approach to counter optimism bias is to engage in "devil's advocate" (Baybutt, 2016) type behavior, highlighting the potential for realistic personal losses (paychecks), damage to corporate reputation (stability of the company), and questioning of leadership (stability of management) occurring as the result of accidents and poor safety culture. By highlighting the possible methods and consequences of failure, system 1 thinking is engaged via realization 
that this behavior is outside of safety "norms: and providing "incentives" to avoid personal and financial losses.

It is important when utilizing MINDPACE as a tool to combat biases, that exaggeration be avoided so that participants do not evaluate the system as a "scare tactic" or extreme measure. Company-wide, management accepted goals should be evaluated for MINDSPACE solutions with real-word, believable outcomes that build trust in the MINDSPACE system because it is aligned with overall organizational goals.

Engaging MINDSPACE to minimize optimism bias when establishing (and maintaining) a just culture means having a system 1 program in place to consistently remind culture designers that the company is statistically vulnerable to negative events. This understanding should be the catalyst for healthy and more ingenious hazard and risk analyses and mitigation measures during the establishment of just culture itself. MINDSPACE recognizes that there are inherent hazards and risks in the establishment of potential solutions in that the answers are susceptible to biases in design, construction and implementation.

\section{MINDSPACE and Planning Fallacy Bias}

Planning fallacy bias involves underestimating resources required while overestimating the benefits (Emmons et al., 2018). When the task is establishing a just culture, planning fallacy may have deeply negative consequences for longerterm SMS effectiveness. For example, consider that leadership is working to establish a VRS as part of a non-punitive just culture that proactively encourages error disclosures. If a strong message is not broadcast from the CEO (the messenger), the promotion of safety is seen as delicate and ethereal. The unquestionable dedication of leadership to the establishment of just culture is paramount because it acts on the instinctive reflex to believe or not to believe the messenger, the head of the company (a system 1 process).

To support the establishment of a just culture and to aid in combating planning fallacy, organizations should consider establishing working teams to default to a risk adverse position automatically. For example, if a helicopter work crew is working on a live electrical conductor, any member of the crew should have the authority to stop the entire work process at any time and discuss the issues with no penalties in benefits (pay or working hours). This default to safety represents support of the just culture from an organizational level and builds trustworthiness with employees that "safety is the norm." Use of the default mitigation tool also assists in alleviating the planning fallacy bias by recognizing the error in resources allocation and effectiveness of procedures, even if it is during a work process.

\section{MINSPACE and Anchoring Bias}

Anchoring bias causes people to base conclusions on certain data points that may be factual or non-factual or on previous experiences (Darveau \& Hammond, 2017). These anchors can form as a result of a messenger (individual or company 
policy), partial information, or a static culture that promotes the idea of circular logic like this is the way we have always done it around here and if it's not broken, don't fix it. Baybutt (2016) noted that anchoring may lead to a type of group or herd mentality that precludes innovation and organizational improvement.

For aviation companies, anchoring bias can result in complacency that is a key enemy, impacting safety and profitability at the same time (Darveau \& Hammond, 2017). Sometimes, the anchoring can result from a lack of information. In these particular cases, a system 1 approach to combat anchoring would be to develop systems through which intelligence is gained about competition. This information about competitors would provide a steady stream of new information which would combat anchoring bias and would act on the system 1 cognitive reflex to "protect" corporate homeland and its customers (incentives, salience, ego) (Dolan et al., 2010; Liu et al., 2017).

Although the topic could be mentioned in other sections of this report, the discussion about anchoring bias seems an appropriate time to mention the strong influence of entrepreneurs. Small to mid-sized companies can be especially vulnerable to the strong leadership styles of entrepreneurs who may bypass normal, internal company processes established to guarantee best case business practices. This strong anchoring effect can lead others in leadership positions to accept this influence and make allowances that retard safety and the establishment of a just culture.

An example of entrepreneurial influence on a just culture would occur if a business owner directly hires a friend in a safety-sensitive position, bypassing normal hiring defaults and processes. An entrepreneur sought to limit safety oversight through a political connection in 1995, which resulted in a charter plane crash, killing three doctors (Brasher, 1995). Since aviation entrepreneurs have legal powers as business owners, they can be dangerous catalysts for excessive risktaking and just culture failures.

\section{MINDSPACE and Ambiguity Bias}

Ambiguity bias (or effect) is related to the identification of "high consequence, low probability" events that are beyond a decision-maker's control or breadth of knowledge (Emmons et al., 2018, p. 64). Ambiguity bias occurs when decisions are made on limited data in favor of known probabilities for favorable outcomes. People tend to avoid choosing an outcome that has limited information. Employees will tend to ignore, or refuse to participate in just cultures with complicated policies or systems, choosing the status quo over a new, more ambiguous method of operations.

Impeding ambiguity when setting up just cultures can be facilitated with use of the MINDSPACE intervention strategies. The key to the ambiguity bias is clarity and clarity demands information. Just cultures should have clear, well-explained policies that treat participants equally and are transparent. Voluntary reporting 
systems (VRSs) should be anonymous and thoroughly explained from system architecture to collection of data and final disposition of reports. Strategists may choose any number of MINDSPACE combinations to achieve these outcomes.

When combatting ambiguity bias, it may be especially useful to maintain a high level of transparency in order to facilitate trust in the just culture. The use of messengers and incentives could accomplish transparency by providing feedback about every VRS error report. The emphasis on positive outcomes for VRS reporting would also provide salience to just culture operations by reinforcing trust by providing transparency and real-life corporate benefits to just culture implementation. Scheduling different members of management and labor discuss these outcomes would also provide an element of $e g o$, further reinforcing adoption of non-punitive thinking.

\section{Conclusions}

Systemic human biases impede objective decision-making at organizational levels, acting as barriers to establishing just cultures. The most common human biases at the organizational level identified in this research were optimism bias, planning bias, planning fallacy bias, and ambiguity bias. Various strategies exist for managing biases that act as barriers to just culture, a pre-requisite for effective aviation SMSs. Two different approaches are normally referenced when dealing with the impact of human biases: system 1 and system 2 solutions.

System 1 solutions are countering mechanisms that are based on heuristics, a human-based evolutionary process that has resulted in impulse and habit-based cognitive shortcuts designed to process decisions rapidly. System 2 thinking is thought of as being the "traditional" basis of solutions to human biases and involves the rational and deliberate aspects of human deliberation.

The purpose of this paper was to identify and advocate a system 1 methodology that may assist in countering human biases that act as barriers to the establishment of just cultures and effective aviation SMS systems. MINDSPACE was identified in the research as a system comprising of nine, bias mitigation tools. MINDSPACE may be useful within the aviation industry in reducing the amount of human biases that impede the establishment of just culture.

Many examples could be made regarding the use of MINDSPACE within the decision-making organizational process associated with creating a just culture. No previous research was able to be identified that considered the use of MINDSPACE in dealing with human biases as they pertain to aviation just culture. The author hopes that this intentionally superficial treatment of the subject will motivate others to conduct additional research in evaluating how system 1 cognitive tools may positively impact just culture and overall aviation SMS function.

As the aviation industry begins to experience the changes associated with NextGen, additional tools should be deployed, assisting in motivating human 
behavior toward safety and efficiency. MINDSPACE has proven its ability to counter human biases in other industries and should prove helpful, not only in benefiting just culture, but should have applications in aviation hazard and risk identification and management.

Although MINDSPACE has been shown to successfully counter human biases in a number of industries, this research uncovered cautionary opinions regarding system 1 thinking. Some sources were concerned that system 1 alternatives (including MINDSPACE) artificially manipulate human behavior, is too paternalistic and may have fleeting impacts on reduction of biases. Another concern is that strategists must be well-trained in the application of system 1 solutions and intensely creative in the design of tools, given a particular situation (Dolan et al., 2010).

Despite the concerns above, MINDSPACE and system 1 tools offer a possible wide-spread humanitarian solution for bias reduction in that the approach is not expensive and may be adopted anywhere and anytime. This potential for widespread use offers those with lower levels of education an opportunity to participate in solutions and the amelioration that system 1 solutions offer.

It should also be noted that no research considered by this project promoted the sole use of system 1 or system 2 thinking as solutions excluding one another. Most research advocated a combination of system 1 and 2 solutions as having more noticeable and lasting impact on the totality of organizational culture (Derous et al., 2016; Dolan et al., 2010; Liu et al., 2017).

\section{Recommendations}

The body of research collected for this project identified the role of human biases as barriers to establishing aviation just cultures, inhibiting the effectiveness of safety management systems. Additional research should pursue scientific studies to more thoroughly define methodology for incorporating MINDSPACE system 1 tools into the aviation industry.

During this research, consistencies were noted between the FAA's discussion on human behavior in the Aviation Instructor's Handbook (FAA, 2008) and potential system 1 and 2 biases interventions. Additional analyses beyond this project has the potential to explore the FAA's research in human behavior, learning and communication as useful information for system 1 and 2 behavioral planners within the aviation industry. 


\section{References}

Baybutt, P. (2016). Cognitive biases in process hazard analysis. Journal of Loss Prevention in the Process Industries, 43, 372-377. doi:10.1016/j.jlp.2016.06.014

Bellamy, L. J., Chambon, M., \& van Guldener, V. (2018). Getting resilience into safety programs using simple tools - a research background and practical implementation. Reliability Engineering and System Safety, 172, 171-184. doi:10.1016/j.ress.2017.12.005

Brasher, P. (1995). Pilot blamed for charter crash killing three government physicians. Retrieved from https://www.apnews.com/ 006b6ec703d24c44ad29f44ed6cd1250

Darveau, K., \& Hannon, D. (2017). Barriers and facilitators to voluntary reporting and their impact on safety culture. The International Journal of Aerospace Psychology, 27(3-4), 92-108. doi:10.1080/24721840.2018.1442221

Dekker, S. (2014). Just culture: Balancing safety and accountability. Farnham, UK: Ashgate.

Derous, E., Buijsrogge, A., Roulin, N., \& Duyck, W. (2016). Why your stigma isn't hired: A dual-process framework of interview bias. Human Resource Management Review, 26(2), 90-111. doi:10.1016/j.hrmr.2015.09.006

Dolan, P., Hallsworth, M., Halpern, D., King, D., Metcalfe, R., \& Vlaev, I. (2010). MINDSPACE: Influencing behavior through public policy. Retrieved from https://www.instituteforgovernment.org.uk/sites/ default/files/publications/MINDSPACE.pdf

Emmons, D. L., Mazzuchi, T. A., Sarkani, S., \& Larsen, C. E. (2018). Mitigating cognitive biases in risk identification: Practitioner checklist for the aerospace sector. Defense AR Journal, 25(1), 52-93. doi:10.22594/dau.16770.25.01

Federal Aviation Administration. (n.d). Safety management system components. Retrieved from https://www.faa.gov/about/ initiatives/ sms/ explained/ components/

Federal Aviation Administration. (2008). Aviation instructor's handbook. Retrieved from https://www.faa.gov/regulations_policies/handbooks_ manuals/aviation/aviation_instructors_handbook/media/FAA-H-80839A.pdf

Federal Aviation Administration. (2016). Safety management system. Retrieved from https://www.faa.gov/about/initiatives/sms/explained/basis/

Federal Aviation Administration. (2018). Safety management system. Retrieved from https://www.faa.gov/about/initiatives/sms/

Fisk, P. (2017). The pseudo-nuero science of business thinking...fast or slow, left or right, logic or emotion, system 1 or 2 . Retrieved from 
https://www.thegeniusworks.com/2017/05/the-pseudo-neuro-science-ofbusiness-thinking-fast-or-slow-left-or-right-logic-and-emotion/

Gubbins, C., Harney, B., van der Werff, L., \& Rousseau, D. M. (2018).

Enhancing the trustworthiness and credibility of human resource development: Evidence-based management to the rescue? Human Resource Development Quarterly, 29(3), 193-202. doi:10.1002/hrdq.21313

Howard, R. (2017). The danger of unconscious bias in HR decisions and how to overcome it. Retrieved from https://www.hcamag.com/hr-news/thedanger-of-unconscious-bias-in-hr-decisions-and-how-to-overcome-it244975.aspx

Ioannou, C., Harris, D., \& Dahlstrom, N. (2017). Safety management practices hindering the development of safety performance indicators in aviation service providers. Aviation Psychology and Applied Human Factors, 7(2), 95-106. doi:10.1027/2192-0923/a000118

Jausan, M., Silva, J., \& Sabatini, R. (2017). A holistic approach to evaluating the effect of safety on the performance of safety reporting systems in aviation organisations. Journal of Air Transport Management, 63, 95-107. doi:10.1016/j.jairtraman.2017.06.004

Jones, K. P., Arena, D. F., Nittrouer, C. L., Alonso, N. M., \& Lindsey, A. P. (2017). Subtle discrimination in the workplace: A vicious cycle. Industrial and Organizational Psychology, 10(1), 51-76. doi:http://dx.doi.org.ezproxy.libproxy.db.erau.edu/10.1017/iop.2016.91

Li, Y., \& Guldenmund, F. W. (2018). Safety management systems: A broad overview of the literature. Safety Science, 103, 94-123. doi:10.1016/j.ssci.2017.11.016

Liu, C., Vlaev, I., Fang, C., Denrell, J., \& Chater, N. (2017). Strategizing with biases: Making better decisions using the mindspace approach. California Management Review, 59(3), 135-161. doi:10.1177/0008125617707973

Malos, S. (2015). Overt stereotype biases and discrimination in the workplace: Why haven't we fixed this by now? Employee Responsibilities and Rights Journal, 27(4), 271. doi:10.1007/s10672-015-9264-7

Naevestad, T., Hesjevoll, I. S., \& Phillips, R. O. (2018). How can we improve safety culture in transport organizations? A review of interventions, effects and influencing factors. Transportation Research Part F: Psychology and Behaviour, 54, 28-46. doi:10.1016/j.trf.2018.01.002

National Transportation Safety Board. (2013). Safety leadership. Retrieved from https://www.ntsb.gov/news/speeches/RSumwalt/Documents/Sumwalt_130 523.pdf

National Transportation Safety Board. (2018). Schweizer 269 accident report. Retrieved from https://app.ntsb.gov/pdfgenerator/ 
ReportGeneratorFile.ashx?EventID=20080807X01175\&AKey=1\&RType $=$ Final\&IType $=$ LA

O’Sullivan, M., Ryan, C., Downey, D. G., \& Hughes, C. M. (2016). A change in behaviour: Getting the balance right for research and policy. International Journal of Clinical Pharmacy, 38(5), 1027-1031. doi:10.1007/s110960160351-0

Ranney, J. M., Zuschlag, M., Coplen, M., \& Nelson, C. (2018). Combined peerto-peer feedback and continuous improvement associated with reduced injuries at Amtrak-Chicago. Safety Science, 107, 130-144. doi:10.1016/j.ssci.2017.06.010

Reason, J. (1990). Human error. Cambridge, UK: Cambridge University.

Robertson, M. F. (2016). Safety professional's perception of the relationship between safety management systems and safety culture. Journal of Aviation Technology and Engineering, 6(1) Article 2. doi:10.7771/21596670.1137

Stolzer, A., \& Goglia, J. (2016). Safety management systems in aviation. New York: Routledge.

Vlaev, I., King, D., Dolan, P., \& Darzi, A. (2016). The theory and practice of "Nudging": Changing health behaviors. Public Administration Review, 76(4), 550-561. doi:10.1111/puar.12564

Waddington, J. G., Lafortune, J. F., \& Duffey, R. (2009). Institutional failure: Are safety management systems the answer? Paper presented at the 30th Annual Canadian Nuclear Society Conference and 33rd CNS/CNA Student Conference, Calgary, Alberta. 